\title{
Normative Objectivity Without Ontological Commitments?
}

\author{
Georg Gasser $^{1}(\mathbb{0}$
}

Published online: 9 March 2017

(C) The Author(s) 2017. This article is an open access publication

\begin{abstract}
Several non-naturalist philosophers look for ways to maintain the objectivity of morals without making any (robust) ontological commitments. Recently Derek Parfit proposed an account of non-ontologically existing irreducible moral properties. My first aim in this paper is to outline that such an account is doomed to fail. My second aim in this paper is to argue that irreducible moral properties can be integrated with adaptions into an ontological framework such as E.J. Lowe's four-category ontology. If it can be shown that irreducible moral properties have a proper place in such an ontology, then there is no need to distinguish between an ontological and non-ontological mode of existence, which, in turn helps to eschew the obscurities that this distinction brings in its wake.
\end{abstract}

Keywords Non-naturalistic moral realism - Derek Parfit · Moral standards as universals · Quietism

\section{Introduction}

Contemporary discussions of moral realism are strongly influenced by Mackie's argument from queerness. The argument has two prongs: one epistemological, and one ontological. The epistemological prong directs our attention to the question of how we are able to access moral properties if these are different from natural ones. The ontological prong asks how moral properties fit into our natural world. If an action is an instance of deliberately

Georg Gasser

georg.gasser@uibk.ac.at

1 Institut für Christliche Philosophie, Karl-Rahner-Platz 1, 6020 Innsbruck, Austria harming an innocent person for no reason, then this action is morally wrong. What is the relationship between the natural properties of the action and the moral property of its being wrong?

The naturalistic response to these worries is straightforward: when it comes to morals, there is just one kind of property involved, namely natural properties. Any worries about how moral properties fit into a natural world are illfounded. As a consequence, the claim that there are moral properties needs to be interpreted in some other way. A naturalistic moral realist will claim that there are moral properties, but propose that they are either entirely reducible to natural ones or ontologically continuous with natural ones. A naturalistic expressivist might think that talk of moral properties is nothing but an expression of one's subjective attitude and a response to an action's natural features. A constructivist along Kantian lines, by contrast, would say that talk of moral properties ought to be taken seriously because it is practically necessary for exercising one's agency as a rational and moral subject in our natural world. Whatever interpretation is given on a naturalistic view, such a view yields the result that moral properties do not exist in their own right, but exist only by way of reduction to something else.

The non-naturalistic response to these worries is less straightforward: first, non-naturalistic moral realists have had a hard time spelling out the connection between natural and moral properties. Is this connection one of supervenience? Constitution? Grounding? Brute co-variation? Second, they must ward off the objection that moral properties are entities "of a very strange sort, utterly different from anything else in the universe" 1 because of their apparent inherently prescriptive nature.

\footnotetext{
${ }^{1}$ Mackie (1977, 38).
} 
These issues have led several non-naturalist philosophers to look for ways to maintain the objectivity of morals without making any (robust) ontological commitments. Thomas Nagel's view of objective values is one example of such an attempt. ${ }^{2}$ Nagel explicitly states that values, in order to be objective, must be objective in their own right, and not in anything else. However, he warns against drawing any ontological conclusions from this view, such as understanding values in terms of Platonist forms. ${ }^{3}$ Nagel does not posit any moral entities over and above the natural entities in the world. Rather, he suggests that moral realism consists in a detached conception of life and the world which ideally corrects our egocentric desires and other idiosyncratic features of our particular perspective. In doing so, it enables us to discern normative reasons which tell us, rightly, how we should act. Nagel's strategy is thus to explain the objectivity of values by relying on an epistemic notion of objectivity rather than an ontological theory of values. He thinks that the existence of objective normative reasons does not require substantive ontological commitments. ${ }^{4}$

A non-ontological version of non-naturalistic moral realism along Nagel's lines is attractive for several reasons. First, it is easier to defend (and to accept) because it incurs no ontological burden. Second, due to its lack of any ontological commitments, such a view allows us to address explanatory questions about the prescriptive nature of moral facts in purely normative terms. The normative realm is no longer held hostage by naturalistic realism or by ontological objections derived from such realism.

Yet the claim that there are objective values or normative truths whose existence carries no ontological weight is difficult to parse. My first aim in this paper is to highlight this difficulty by outlining one prominent proposal-Derek Parfit's recent non-ontological account of irreducible moral properties. The second aim is to argue that irreducible moral properties can be straightforwardly integrated into an ontological framework. Here I make use of E. J. Lowe's well-known four-category ontology. If it can be shown that irreducible moral properties have a proper place in such an ontology, an answer to Mackie's argument from queerness

\footnotetext{
${ }^{2}$ Svavarsdóttir (2007) provides a detailed discussion of Nagel's account.

${ }^{3}$ Nagel (1986, 139).

${ }^{4}$ Scanlon $(2003$, 9), holds a similar view. He writes: "It might be said that moral judgments, if they were understood as making truth claims, would involve metaphysical claims that go beyond what is guaranteed merely by their correctness according to ordinary moral criteria: to claim that they are true would be to claim for them an 'intrinsic metaphysical gravitas'. [...] But moral judgments as I understand them do not depend on such a view of the world, nor do they need the support of other metaphysical claims. [...] The kind of gravitas that they require is thus not metaphysical but normative."
}

can be given. Then philosophers might be less reluctant to posit irreducible moral properties, which, in turn, helps to avoid having to distinguish between ontological and nonontological existence and thus also to eschew the obscurities that this distinction brings in its wake.

\section{Parfit's Ontology of Moral Properties}

Parfit offers the following answer to the objection that moral properties are a very strange sort of entity. If we consider sentences such as

i. The planet Venus exists.

ii. There are four vipers in this plastic container.

iii. There are three prime numbers between one and five.

iv. Ohm's law existed before it was first formulated by Ohm.

v. The symphony "Eroica" has existed ever since Beethoven wrote it in 1802/03.

vi. The possible course of action of my going for a hike tomorrow exists.

vii. The number seven is blue.

viii. There exists a triangle with four sides.

then we might come to believe that different meanings of "to exist" are involved here. Most people would agree that the entities mentioned in (i) and (ii) exist. There is little doubt that the planet Venus, plastic containers and snakes exist. As material entities they are easily accessible-we can see, touch, and study them. We are able to experience their causal impact in one way or another. Similarly, most people would hold that an entity such as the one posited in (viii) does not exist because strong reasons speak for the metaphysical impossibility of a triangle to have a greater or smaller number of sides than three. Likewise, the item in (vii) cannot possibly exist because numbers-as all other abstract entities-are neither blue nor colored more generally.

However, people become less certain when asked whether the items in (iii) - (vi) exist. (iii) is clearly a true statement, but in what sense do entities like numbers exist? They do not exist in space and time, and therefore one might be inclined to say that their existence appears ontologically less robust than that of material objects. What about the item in (iv)? There is no doubt that Ohm's law is valid. Since it depends on the existence of conductors and their specific properties, once again, one might claim that its mode of existence is less robust than that of the material objects on which it depends. One might find it reasonable to ascribe an even less robust mode of existence to a symphony, because its existence depends in a yet more radical way on its composer than Ohm's law does on the material 
objects. A natural law, we can claim, obtains independently of us; it is there for us to discover. A symphony, by contrast, must—like any other artifact—be invented by us. Similarly, we might say that not only the coming into being as such but also the continuous existence of artifacts depends on people perceiving them as these specific artifacts. Once people have disappeared from this planet and all traces of human civilization have vanished, then it seems right to say that the Eroica has gone out of existence whereas the state of affairs described by Ohm's law continue to hold. Finally, things appear even more complicated with (vi). We are able to refer intentionally to possible courses of future actions or future states of affairs. Does this ability justify us in believing that these items have any ontological robustness, even though they exist only in the realm of the possible?

The conclusions one draws will depend on one's fundamental ontological views. Two important ontological views are what Parfit calls "actualism" and "possibilism". Actualism says that

[t]o be, or to exist, is to be actual, so there cannot be anything that is merely possible. ${ }^{5}$

According to actualism, the entities in (i), (ii), (iv) and (v) exist, because "to exist" means to exist at some particular instant. Disputable, instead, is the ontological status of abstract entities like numbers as in (iii), for abstract entities are not possible entities but they exist outside time and space.

Possibilism, by contrast, is the view that

[t]here are some things that are never actual, but are merely possible. There are some things that might happen but never actually happen, and some things that might exist but never actually exist. ${ }^{6}$

An advocate of possibilism does not reject the existence of actual entities. He or she claims that such entities do not exhaust what there is in the world. On this view, actual entities exist in an ontologically different way from merely possible ones.

Returning to our list of statements, a possibilist would surely embrace (i), (ii) and (iv)-(vi). It is unclear what he or she should say about (iii), because, although abstract objects such as numbers do not exist in an actual sense as concrete objects do, they are not merely possible uninstantiated entities either.

Parfit supports possibilism by the insight that we are able to compare different possible courses of action and that we might be happy to have chosen one course over another. Racking our brains over which possible action to

\footnotetext{
5 Parfit $(2011,467)$.

${ }^{6}$ Parfit $(2011,467)$.
}

choose, and being happy or sad about the one we have chosen, would hardly be justified if there were no other possible courses of action for us to choose against.

Another important distinction which Parfit discusses is "the single-sense view" and "the plural-senses view". The former says that

[t]he words 'there are' and 'exist' must always be used in the same single sense. ${ }^{7}$

This view fits well with actualism. Since actualism says that only actualized entities exist, all of these entities exist in one and the same sense.

The plural-senses view, for its part, claims that

[t]here is one wide, general sense in which we can claim that there are certain things, or that these things exist. We can also use these words in other, narrower senses. For example, if we say that certain things exist in what I shall call the narrow actualist sense, we mean that these things actually exist as concrete parts of the spatio-temporal world. ${ }^{8}$

The plural-senses view fits well with possibilism. Once we accept different senses in which entities can exist, it is only a small step toward accepting that possible entities exist, albeit in a different sense from actual ones. In this case one might claim that both kinds of entities exist in the wide general sense, but only the narrow actualist sense of existence can be ascribed to concrete entities.

Parfit embraces both possibilism and the plural-senses view. This allows him the greatest possible ontological flexibility: a liberal ontology such as this can include possible entities, because the main question is not what kinds of entities possibly exist, but rather how they exist. ${ }^{9}$ That this "how" question has utmost importance for Parfit becomes clear in his discussion of the ontological status of abstract objects. Abstract entities are neither possible nor concrete. They exist in a robust but abstract sense. ${ }^{10}$ However, it is not clear what it might mean to say that they exist in a similar sense to that of concrete entities except that the former are outside of space and time. Parfit suggests that there might be no determinate answer to the question of whether abstract objects exist at all. ${ }^{11}$

\footnotetext{
7 Parfit (2011, 469).

8 Parfit $(2011,469)$.

9 See Parfit $(2011,474)$.

10 Parfit $(2011,745)$, writes: “[...] unlike entities that are merely possible, some of these abstract entities can be claimed to be actual in another, wider sense".

11 Parfit (2011, 476-479). Such a claim might be less surprising than one is first inclined to think, for some questions-as the sorites-paradox suggests - may have no clear answer beyond that supplied by convention.
} 
If taken for granted, however, this agnostic claim can still fit well with a form of cognitivism. Cognitivism, generally understood, is the thesis that some kind of claim can be true or false independently of our attitudes and states of mind. If I claim that a glass of wine is on the table before me, then this claim is true if a specific ontological fact holds, namely, that there is indeed a glass of wine on the table before me. Parfit dubs this view "metaphysical cognitivism about truth", because the truth conditions for such a claim require a specific ontological state of affairs to obtain. However, there are also truths which do not depend in any way on us or on any other concrete things-think of the necessary truth of logical or mathematical truths. For Parfit, such truths do not involve any ontological mysteries, because there are no states of affairs which correspond to them. He thus contrasts metaphysical with non-metaphysical cognitivism; the latter says that

[t]here are some claims that are, in the strongest sense, true, but these truths have no positive ontological implications. ${ }^{12}$

Thus, according to non-metaphysical cognitivism one might claim that $\mathrm{X}$ is true, and there is some sense in which $\mathrm{X}$ exists but this sense of $\mathrm{X}$ 's existence has no ontological meaning. It is true that there are three prime numbers between one and five. This truth-claim commits its proponent to the claim that numbers and their specific properties exist in some non-ontological sense.

In the light of these reflections Parfit distinguishes between three different meanings of "to exist" that are relevant for present purposes. Concrete entities exist in the narrow actualist sense; possible entities exist in a wide sense; and abstract entities exist

not only in the wide sense, but also in a distinctive, non-ontological sense. ${ }^{13}$

The crucial insight is that, according to non-metaphysical cognitivism, a claim can be true in itself and not in virtue of certain states of affairs obtaining. That is,

[t]ruths need only be true. ${ }^{14}$

Parfit applies this thesis to irreducibly normative claims by way of an analogical argument. He writes:

There are some claims that are irreducibly normative in the reason-involving sense, and are in the strongest

\footnotetext{
12 Parfit (2011, 479).

13 Parfit $(2011,480)$. I take it that Parfit has this sort of threefold distinction in mind, even though he is not entirely clear about whether possible uninstantiated entities, such as a possible palace, exist in the wide non-ontological sense or in a wide ontological sense.

14 Parfit $(2011,482)$.
}

sense true. [...] For such claims to be true, these reason-involving properties need not exist either as natural properties in the spatio-temporal world, or in some non-spatio-temporal part of reality. ${ }^{15}$

Hence, irreducible normative truths are solely and exclusively true in themselves; neither natural facts nor irreducible normative ones are needed for making them true.

\subsection{A Critical Assessment of Parfit's Account}

Here is a brief summary of Parfit's non-metaphysical cognitivism:

1. There are true normative statements.

2. The normativity of normative statements consists in irreducibly normative concepts which are reasoninvolving and which belong to their own specific kind.

3. The truth of normative statements implies neither any ontological commitments nor the existence of natural or normative properties which serve as truth-makers for these statements.

I will present two questions about this account. The first concerns the conception of truth it involves. The second asks whether and how true normative statements can exist without having any ontological implications.

The first question can be rephrased as follows: supposing that the non-metaphysical cognitivist is right that there are true normative statements, how do these statements differ from normative statements that are not true? Since the non-metaphysical cognitivist is committed to objective normative truths, relativist theories of truth (such as pragmatic or coherentist accounts) are unsuitable from the outset. The account of first resort for moral realists is generally the correspondence theory of truth. Accordingly, the truth of true statements consists in a correspondence to how things are "out there". A statement's being true is a relational property consisting in the correspondence between some part of reality and the propositional content of the statement. Fortunately, getting a grip on the notion of truth needed by non-metaphysical cognitivism does not require extensive details concerning how to spell out this notion of correspondence. If true normative statements have no ontological implications, then there is simply no part of reality to which such statements correspond.

In a recent article Suikkanen analyses the prospects of operating with a different notion of truth, namely deflationism. ${ }^{16}$ Deflationism says that truth has no specific "deeper"

\footnotetext{
15 Parfit (2011, 486).

16 Suikkanen (2016)
} 
nature; it consists neither in a specific relation nor a particular property. No corresponding fact must hold, nor must a true statement cohere with a set of other statements, nor is truth the outcome of an ideal rational inquiry. The statement "This spider is poisonous", is true just in case the spider is poisonous, full stop. The truth predicate enables us to step away from talking about language and toward talking about reality. However, as Suikkanen points out, such a deflationist notion of truth puts non-metaphysical cognitivists in a predicament:

If they understand normative facts in a deflationist way, they cannot distinguish their view from non-naturalistic moral realism. The reason is that they are no longer entitled to claim that, since there are no irreducible normative facts to serve as truth-makers, non-naturalistic moral realists are wrong about moral statements. After all, non-metaphysical cognitivists already suppose that talk of normative facts is just a more cumbersome (and tentatively misleading) way to express the insight that non-naturalistic moral realism does not go beyond the ontological commitments of nonmetaphysical cognitivism. A deflationist understanding of normative facts does not add anything to the ontology of deflationist non-metaphysical cognitivism.

To avoid such a consequence, a non-metaphysical cognitivist might suggest an inflationist understanding of normative facts. According to such an understanding, if normative facts existed then they would be part of reality, but in fact - the claim goes-no such facts exist. But a view combining deflationism about truth with inflationism about normative facts seems to collapse into an error theory. Such a theory holds that ordinary moral statements involve a builtin claim to normative objectivity which non-cognitivism and naturalism fail to capture, but that this claim is always false because there are no irreducible normative facts. ${ }^{17}$

An inflationist non-metaphysical cognitivist also holds that ordinary moral statements are objective, but he denies that this claim to objectivity has any ontological implications. Thus, the error theorist's world is ontologically indistinguishable from the non-metaphysical cognitivist's; nor do their understandings of the nature of normative claims seem to differ. Nevertheless, a non-metaphysical cognitivist aims at clearly distinguishing her account from an error theory. As Parfit remarks, moral truths need only be true; it is here that error theory parts ways from non-metaphysical cognitivism because error theory denies that there are any such truths. Therefore, non-metaphysical cognitivism requires a theory of truth which is more robust than deflationism because it presupposes a truth property which marks the difference to error theory. In particular, a nonmetaphysical cognitivist notion of truth has the following

\footnotetext{
$\overline{17}$ Mackie (1977, 48-49).
}

features: truth is (i) a non-natural property, which (ii) does not involve any correspondence-like ontological commitments, (iii) is genuinely stance-independent in contrast to relativist accounts, and (iv) is robust enough to avoid collapsing into error theory. These requirements smack of primitivism about truth: if normative statements are true, then they are true in a way that is irreducible, simple, sui generis and non-ontological.

If non-metaphysical cognitivism was meant to be less queer than non-naturalistic moral realism supposedly is, then we might wonder whether the appeal to primitivism about normative truth succeeds at this aim. The claim that normative statements are true in virtue of irreducibly normative properties is comprehensible, even if it conflicts with our other knowledge about the world and must consequently be rejected. ${ }^{18}$ Primitivism about truth, however, is hardly even comprehensible to begin with. It has queerness written all over it.

The second question asks: what does it mean to claim that there are true normative statements with no ontological implications? Surely, if a normative statement is true, then certain things would follow from it, ontologically speaking. Consider the statement that Professor Q's lectures are instructive and enjoyable and you should therefore attend them. This statement has a normative character and presupposes (i) that Professor Q exists, (ii) that he is giving lectures, and (iii) that his lectures have the properties of being instructive and enjoyable.

Or suppose that it is true that there is someone who supports the poor and because of this she is morally good. This is a moral statement and if it is true, then it provides everyone who can afford to support the poor with a reason to do so. This statement too has several ontological implications, namely that there are (i) people who can afford to support the poor, (ii) poor people in need of support, (iii) actions involving support of the poor, (iv) the normative property of being good, and (v) the normative reason for supporting the poor, namely that one should do so.

At this point Parfit might specify that he is not denying wholesale that true normative statements have ontological implications. Rather, his claim is merely that it is crucial to distinguish between ontological implications regarding the natural realm and alleged ontological implications regarding the normative realm. Given the plural-sense view, of the previously mentioned implications, (iv) and (v) concern the normative realm and therefore exist in a distinctive, non-ontological sense, whereas (i)-(iii) exist in the narrow actualist sense.

\footnotetext{
18 Mackie (1977, 48), for instance, speculates that the existence of irreducible normative facts could be defended with recourse to God but that such a defense is not viable since theism cannot be defended.
} 
Thus, the central question is what it means for normative truths to exist in a non-ontological sense. Parfit for his part uses the following example to motivate an ontologically layered understanding of reality ending with a non-ontological sense of existence:

There was a palace designed by Wren to replace the burnt Palace of Whitehall, but this palace was not built and never actually existed. ${ }^{19}$

According to Parfit, an advocate of the single-sense view would have to claim that there existed a palace that was never built and that therefore-in the same univocal sense of "exist" - the palace never existed, which is a contradiction. However, there are various ways to avoid such a contradiction. An actualist might say that the above claim must be re-interpreted because (merely) possible entities do not exist. What there was, ontologically speaking, was a design for a palace and a mental representation in Wren's mind. Alternatively, a friend of possible objects might say that Wren's possible palace exists but remains uninstantiated; that is, that, in one and the same sense of "exist", no actual palace exists. These alternative ways to interpret the alleged existence of possible objects indicate that Parfit's plural-sense view is insufficiently motivated.

In addition-and this objection appears stronger-a plural-sense view will hardly convince philosophers who regard the existence of possible objects as ontologically obscure that the attribution of an ontologically lowergrade existence makes possible objects less ontologically obscure. The problem is the very concept of a possible entity, and hence any mode of existence such an entity might enjoy will appear as problematic too. Metaphysicians who reject realism about numbers do so because they find the very idea of a mind-independent number ontologically obscure. To claim that numbers exist after all but in a different way than concrete entities will be of no help here; on the contrary, this claim will increase the mystery, since it implies that things can exist non-ontologically.

To further illuminate the problematic notion of nonontological existence, compare Parfit's non-metaphysical cognitivism with moral error theory. Parfit's account does not share the error theory's conclusion that there are no irreducibly normative truths. Accordingly, non-metaphysical cognitivism appears to be richer than the error theory in some sense, since the former takes reality to consist of natural entities as well as normative truths. Interestingly, however, on the ontological level there is no difference between an error theory and Parfit's account; for Parfit claims that normative truths bear no ontological weight. One might be puzzled, then, about what the difference between these two views amounts to. For it is sensible to assume that the world according to error theory should bear some marked difference from the world according to Parfit's non-metaphysical cognitivism.

In summary, Parfit's non-metaphysical cognitivism tries to avoid significant ontological costs by arguing that, although irreducibly normative truths exist, they do so in a non-ontological sense. As I have argued, however, it is anything but clear what it means for something to exist in this way. Parfit seems to introduce a third, non-ontological realm of reality beyond the concrete and the abstract; but this posit, far from demystifying the existence of irreducibly normative truths, makes their existence even more baffling. Parfit's proposal fails: first, it fails to provide the promised explanation of the non-ontological existence of irreducibly normative truth. Second, a notion of non-ontological existence fails to connect with our ordinary views of what might exist. Third, it is unclear how a substantive debate between naturalistic and non-naturalistic moral realists should be rephrased, if not in terms of ontological disagreements. Therefore, I take it that the price exacted by non-metaphysical cognitivism is prohibitive. Non-naturalistic moral realism is not free of ontological costs, after all.

\section{Outlining the Framework for a Moral Ontology}

If irreducibly normative properties exist in an ontological sense, then one might ask what that sense amounts to. To answer this question it makes sense to outline a general ontological framework. One such a framework was recently worked out in detail by E.J. Lowe. His so-called four category ontology is meant primarily to serve as a metaphysical foundation for natural science, ${ }^{20}$ but I submit that, appropriately adapted, it can also provide a framework for an ontology of the normative. Lowe proposes the following fundamental ontological categories: (i) objects or individual substances; (ii) instantiated properties or modes, (iii) kinds and (iv) universal properties or, in Lowe's terminology, attributes. These categories are structurally related to each other in the following three ways:

First, the relationship between an individual substance and its kind, and the relationship between a (non-substantial) universal attribute and its property-instance, is one of instantiation: a particular reef shark is the instantiation of the kind "reef shark", and this shark's particular aggressiveness is an instance of the non-substantial universal attribute of aggressiveness.

\footnotetext{
$\overline{{ }^{20} \text { Lowe (2006). }}$
} 
Second, the relationship between the individual substance and its particular properties is one of characterization. The particular aggressiveness characterizes the individual reef shark of which it is a mode. A parallel relationship of characterization can be found at the level of universals: the universal attribute of aggressiveness characterizes the kind "reef shark" in a general way. Thus, we might say that the relationship of characterization is one between instantiated or uninstantiated properties on the one hand and substances, respectively kinds, on the other.

Third, the relationship between an individual substance and a (non-substantial) universal attribute is one of exemplification. Accordingly, a particular reef shark that instantiates the kind "reef shark" is characterized (among other features) by this individual's specific aggressiveness; the shark thereby exemplifies the universal attribute of aggressiveness. ${ }^{21}$

At this point one might wonder why an ontology should be limited to only these four categories. Suffice it to answer this question with two brief reasons offered by Lowe. The first is that universals are able to account for natural laws and the second is that particulars account for causal relationships. Let us turn to universals first. Take, for instance, the law-like statement that ravens are black. This statement expresses that the (universal) attribute of being black characterizes the (substantial) kind "raven". And the law-like statement that electrons and protons attract each other expresses that the (universal) attribute of attracting each other characterizes the relation between the kind "electron" and the kind "proton". One major advantage of such an understanding of natural laws is that it does not imply an account of constant conjunctions among particulars, which is beset by the problem of how to distinguish between accidental and necessary conjunctions. This understanding of natural laws only has implications for how objects falling under a specific (substantial) kind tend or are disposed to behave in various circumstances, and therefore-a distinction between accidental and necessary conjunctions is not required. ${ }^{22}$

Let us turn to particulars now. This raven's blackness explains various things, for instance, its specific heat balance; its particular instantiation of a shape explains how it flys, and its strength explains its social status within its flock. Particulars are therefore the most suitable sort of entitiy for being causal relata, and a particular substance enters into specific causal relationships because of its determinate property-instantiations or modes.

\footnotetext{
${ }^{21}$ Lowe (2006, 111).

${ }^{22}$ For a detailed discussion of this conception of natural laws see Lowe (2006, 127-136)
}

This ontological framework thus draws an exhaustive and exclusive distinction between universals and particulars. Universals, for their part, are sub-divided into attributes and kinds. Kind-universals are instantiated by individual objects, and attribute-universals by properties-which are themselves divided into non-relational and relational modes. Events, and actions as a specific sub-category of events, fit into this ontological scheme as entities dependent on other entities, namely objects and their modes. If a particular object changes by losing or acquiring a particular property (or both), or if it undergoes a change in some particular relation it bears with some other particular object (i.e., once it assumes a new relation-mode), then an event occurs. $^{23}$

I propose now to apply this ontological framework to normative discourse. We may start with the non-naturalistic moral realist's claim that there are irreducible normative standards and properties. In the light of the above framework, irreducible normative standards are kind-universals and they are characterized by the attributes of being good or bad. Here is a first example of how this classification works: we may assume that there is a normative standard for computers telling us whether a computer is good, that is, properly functioning, or not. ${ }^{24} \mathrm{~A}$ computer satisfies the standard of goodness for computers if it processes quickly, does not crash, and has a large memory and a high graphic resolution. Thus, the kind "computer" characterized by these attributes is a good kind of computer. If the computer in my office displays these properties, it instantiates a good kind of computer.

Analogously, we can say that there are the moral standards for actions. These standards specify action-types which qualify as morally good or bad and by doing so they provide guidelines for agents looking to comport their decisions and actions with the demands of morality. Employing Shafer-Landau's and Cuneo's concept of a moral fixed point, we might identify these standards with such fixed points. ${ }^{25}$ They must find a central place in any moral system applying to beings like us in a world like ours because they set the boundaries of any competent moral understanding. The application conditions of these standards are determined by their normative content because they contain inbuilt conceptual constraints on what could classify as morally good or bad behavior.

Here are a few examples of such moral standards for us: the action-type of supporting the poor is characterized by the attribute of being morally good. So is the action-type

\footnotetext{
${ }^{23}$ On this see Lowe (2002, Chap. 12 and 13).

24 The example is taken from FitzPatrick $(2006,186)$.

25 Cuneo und Shafer-Landau (2014).
} 
of expressing gratitude to a benefactor. The action-type of hurting people for lust, by contrast, is characterized by the attribute of being morally wrong. The same applies to the action-type of torturing a person for no serious reason. Accordingly, if Elias is buying groceries for someone who cannot afford them, then his action instantiates the standard of moral goodness and is characterized by the mode of being morally good. If Emile, instead, deliberately offends a fellow student for sheer pleasure, then his action instantiates the normative standard of moral badness and is characterized by the mode of being morally bad.

These reflections indicate that an ontological framework such as Lowe's which was primarily designed for natural science can also form the basic framework into which an ontology of the normative can be slotted. What about the argument that normative entities are too queer to be admitted by a scientific worldview? There are many responses to this line of thought. I limit myself to three.

\subsection{Three Possible Objections}

The first response is this: once we acknowledge that universals have an important role to play in the ontological foundations of natural science, the argument from queerness loses much of its force because it is not exclusively directed against the existence normative entities. First, consider the causal efficacy test against normative entities. It excludes normative entities from the table of any serious ontology because they do not possess independent causal powers but are instead inherently causally inert. But universals are causally inert too, since they do not enter into causal relations. So, the causal efficacy test excludes universals in general from ontology.

Consider now a second objection which is related to the first but has an epistemological thrust. It says that we cannot have any knowledge about normative entities, because all knowledge derives from a causal transferal of information. If normative entities are causally inert, then there can be no causal transferal of information about them. But we may respond, as above, that the same goes for universals in general. So a causal theory of knowledge is unsuitable as a general theory of knowledge; such a theory is inappropriate for knowledge about anything but concrete particulars, since these are the only entities capable of entering into causal relations. Again, the argument from queerness is not directed against normative entities in particular but abstract entities in general. If certain kinds of universals, however, play an important role in the ontological foundations of natural science, then the argument from queerness is too coarse-grained because it excludes too much.

Here is my second response: one might suspect that the causal-efficacy test imposes an unduly naturalistic stricture on ontology in general with the effect that it promotes a better understanding neither of natural science nor of human life. I have already advocated accounting for natural laws at the abstract level; suffice it here, then, to say the following: human life is permeated by normative standards telling us what we should do and how we should evaluate all kinds of matters. Standards of goodness for computers tell us how to evaluate computers. A standard for good epistemic practice says that we ought to believe the conclusions of sound arguments. A standard of prudential reasoning says that we should pursue the most efficient means for realizing our aims. Such standards are ubiquitous in our lives. Moral standards are just one among many other sorts of normative standards.

Clearly, none of these standards causes anything of its own accord. The most we can say about their causal efficacy is that, once an agent has appropriated these standards, they might explain this agent's reasoning, decisions, or behavior. ${ }^{26}$ It is a matter of intense dispute whether we can account for this sort of efficacy in causal terms; one relevant question here is whether-if we can account for it this way at all-we can only do so by positing another sort of causation beyond the mere efficient. ${ }^{27}$

Regardless of what sense is appropriate for ascribing causal powers to normative standards, it is reasonable to assume that standards exist. Imagine that the epistemic principle that one should proportion one's beliefs to one's evidence is true. This principle is true even if no person in fact abides by it. People should follow this principle, but if for whatever reason no one does, then it still makes sense, given the ontological framework proposed here, to think that this principle exists at the universal level even though it is not instantiated by any particular performed reasoning at the moment.

I conclude that the causal-efficacy test is not suitable as a general ontological test, for it excludes from existence anything but those concrete particulars which are in some way accessible to us in terms of efficient causation. ShaferLandau underlines this point when he writes:

[...] the allegiance to the causal test entirely eliminates the normative realm. But this is highly implausible. [...] If there is any such thing as a genuine rea-

\footnotetext{
${ }^{26}$ Kim $(1998,78)$, stresses this point: "For when you deliberate, you must call on what you want and believe about the world-your preferences and information-from your internal perspective, and that's the only thing you can call on. [...] Reasons for action, therefore, are necessarily internal reasons, reasons that are cognitively accessible to the agent. That is one crucial respect in which reasons for action differ from causes of actions: reasons must, but causes need not, be accessible to the agent."

27 One comprehensive overview of critical voices regarding the (standard) "reasons-are-causes"-account can be found in Sandis (2009).
} 
son, the test must fail. Alternatively, if the test is retained, then such reasons must be capable of passing it. And then the causal argument against moral facts evaporates. ${ }^{28}$

Here is the third response: evaluating an object as good does not consist in a set of natural properties, and certain moral properties supervening on it. ${ }^{29}$ The same set of natural properties could be instantiated by many different objects, but not all of these properties would consequently be considered to be good. A porcelain knife is a good knife if it is sharp; but if the edge of a porcelain vase is sharp, this would be considered very bad indeed. Hence we may say that the fact that a given object is good consists in more than just a specific set of natural properties; in addition, there are standards of goodness for the kind of object that is instantiated by this specific object.

An analogous case can be made for human actions. The fact that a human action is morally good consists not merely in the set of natural properties constituting the human action but also in an appropriate standard of moral goodness instantiated by the action in question. Say that Emile publicly mocks a fellow student. If this action is considered bad, then we may say that its badness does not consist only in its natural features, but also in their relationship to some appropriate standard of moral goodness for human actions, a standard which Emile's behavior has violated. Fitzpatrick emphasizes that, in order to grasp the difference between describing and evaluating a behavior, it is decisive that in the latter case we are

doing so according to objective standards of the sort that could be authoritative for rational agents. ${ }^{30}$

If this line of reasoning is correct, then natural facts cannot exhaustively constitute normative facts. Note that this account does not involve the claim that Emile's behavior was bad in virtue of being unfair, hardhearted and cruel plus one additional normative property X. An explanation of the badness of Emile's behavior is complete as long as we refer to the natural features of his behavior. This explanation does not need an additional non-natural property. Note also that the assumption of an additional normative property does not suggest that the property of badness can exist in perfect isolation and independently of the action's natural properties. Rather, the latter determine the normative property for the action's moral character (and so they do in regard of any other normative properties, such as prudential ones, which the action has). This claim, moreover,

\footnotetext{
28 Shafer-Landau (2007, 219).

${ }^{29}$ Here I mainly adopt the argument in FitzPatrick (2006, 190-194).

30 FitzPatrick $(2006,189)$.
}

is no concession to naturalism about moral ontology. Rather, it merely clarifies the specific way in which normative properties relate, at the level of particulars, to natural ones. If no action were performed, then no corresponding normative property could be instantiated; so no reference to an appropriate standard of goodness for human behavior could be made. The claim that an action's natural features are all that is needed to describe what has happened does not commit us to a naturalistic account of moral realism. Normative properties do not primarily contribute to the description and explanation of what has happened-rather, they provide an evaluation of it.

The upshot of these considerations is that there are different perspectives involved in describing states of affairs which are subject to normative evaluation such as human decisions and actions, and it is important to keep them separate. To this end Shafer-Landau proposes a distinction between the scientific study of nature on the one hand and the philosophical inquiry on the other. The former perspective explains the natural features of Emile's behavior such as its biological, neurological or psychological features, the latter perspective offers a moral evaluation of it. He writes:

When trying to verify the basic standards that govern the application of moral predicates, we will only secondarily (if at all) advert to what the physicists and botanists and hydrologists say. The conditions under which actions are right, and motives and characters good, aren't confirmed by the folks with lab coats. They are confirmed, if at all, by those who think philosophically. ${ }^{31}$

Empirical inquiry, then, is not the right tool for grasping normative standards and fleshing them out; the tool we need instead is proper ethical reflection. Again: the argument from queerness starts at the wrong place, because it presupposes a purely natural conception of reality as default state. It is rather unsurprising, then, that normative entities find no natural place in it. However, as rational agents our perception of the world is not limited to the empirical, but comprises the normative as well. Our perception of the world is inherently normative. ${ }^{32}$ Thus the actions of a rational agent either instantiate or fail to instantiate the normative standards which determine his or her conceptual framework.

\footnotetext{
31 Shafer-Landau $(2007,213)$.

${ }^{32}$ FitzPatrick (2006, 195), says "that many familiar facts and features of human life, behavior, and experience, which can be the subject of empirical investigation, are also inherently value laden, and as such are the source of objective standards of goodness for us-though these standards can be properly grasped and specified only through correct ethical reflection [...]."
} 


\section{Conclusion}

The notorious argument from queerness has motivated Parfit, among others, to posit irreducible and stanceindependent objective morals which lack any ontological underpinning. Parfit's argument for this proposal appears to draw on the venerable metaphysical tradition that there are different degrees of existence. However, Parfit's account goes beyond this tradition in arguing for an entirely nonontological sense of existence. I have argued that this project is doomed to fail. There is no persuasive account of non-ontological existence available. Even if it is not utterly incoherent, such an account entails a form of "brutism" about non-ontological existence which can hardly address the worries which the argument from queerness articulates. However, as I have argued in the second part of the paper, no move towards a non-ontological sense of existence is even needed. On the basis of Lowe's four-category ontology I aimed to show how normative entities might figure into a comprehensive ontology that allows for both universals and particulars. Analogously to the ontological status of natural kinds and their instantiated particulars, as well as to that of universal natural properties and their instantiated modes, it makes sense to think that there exist normative standards specifying action-types and performed human actions as their instantiated particulars, as well as characterization relations to universal normative properties and their instantiated modes. Once universals are taken for granted, such a view leads to no particular ontological complications. Granted, it expands the ontological universe beyond the realm of the merely natural. A naturalist may find this ontological inflation objectionable. However, there are persuasive reasons in support of an ontology of the normative along these lines, not least that it is needed in a universe populated by rational—and as such moral—agents.

Acknowledgements Open access funding provided by University of Innsbruck and Medical University of Innsbruck.
Open Access This article is distributed under the terms of the Creative Commons Attribution 4.0 International License (http:// creativecommons.org/licenses/by/4.0/), which permits unrestricted use, distribution, and reproduction in any medium, provided you give appropriate credit to the original author(s) and the source, provide a link to the Creative Commons license, and indicate if changes were made.

\section{References}

Cuneo T, Shafer-Landau R (2014) The moral fixed points: new directions for moral nonnaturalism. Philos Stud 171(3):399-443. doi:10.1007/s11098-013-0277-5

FitzPatrick WJ (2006) Ethical realism, non-naturalism, normativity. In: Shafer-Landau Russ (ed) Oxford studies in metaethics. Oxford University Press, Oxford, pp 159-205

Kim J (1998) Reasons and the first person. In: Bransen Jan, Cuypers SE (eds) Human action, deliberation, and causation. Kluwer Academic Publishers, Dordrecht, pp 67-87

Lowe EJ (2002) A survey of metaphysics. Oxford University Press, Oxford

Lowe EJ (2006) The four-category ontology. A metaphysical foundation for natural science. Oxford University Press, Oxford

Mackie JL (1977) Ethics. Inventing right and wrong. Penguin Books, New York

Nagel T (1986) The view from nowhere. Oxford University Press, New York

Parfit D (2011) On what matters. Oxford University Press, Oxford

Sandis C (ed) (2009) New essays on the explanation of action. Palgrave Macmillan, Hampshire

Scanlon TM (2003) Metaphysics and morals. Proc Addresses Am Philos Assoc 77(2):7-22

Shafer-Landau R (2007) Ethics as philosophy. A Defense of ethical nonnaturalism. In: Shafer-Landau R, Cuneo T (eds) Foundations of ethics. An anthology. Blackwell Publication, Malden, pp 210-221

Suikkanen J (2016) Non-realist cognitivism, truth and objectivity. In: Acta analytica. doi:10.1007/s12136-016-0300-5

Svavarsdóttir S (2007) Objective values: does metaethics rest on a mistake? In: Leiter B (ed) Objectivity in law and morals. Cambridge University Press, Cambridge, pp 144-193 